\title{
Malnutrition status and associated factors among HIV-positive patients enrolled in ART clinics in Zimbabwe
}

Kudakwashe C. Takarinda ${ }^{1,2^{*}}$, Tsitsi Mutasa-Apollo ${ }^{1}$, Bernard Madzimaa ${ }^{3}$, Brilliant Nkomo ${ }^{1}$, Ancikaria Chigumira ${ }^{3}$, Mirriam Banda ${ }^{3}$, Monica Muti ${ }^{3}$, Anthony D. Harries ${ }^{2,4}$ and Owen Mugurungi ${ }^{1}$

\begin{abstract}
Background: Sub-Saharan Africa suffers from a high burden of undernutrition, affecting 23.2\% of its population, and in 2015 constituted 69\% of the estimated people living with Human Immunodeficiency Virus (HIV) globally. Zimbabwe, in Southern African has a HIV prevalence of 14.7\%, but malnutrition (under-and over-nutrition) in this population has not been characterized. A nationally representative survey was therefore conducted to determine malnutrition prevalence and associated factors among HIV-positive adults ( $\geq 15$ years) enrolled at antiretroviral therapy (ART) clinics in Zimbabwe.
\end{abstract}

Methods: Height and weight measurements were taken for all enrolled participants who had attended their scheduled clinic review visits. Malnutrition was determined using body mass index (BMI) calculations and classified as undernutrition $\left(<18.5 \mathrm{~kg} / \mathrm{m}^{2}\right)$, normal $\left(18.5-24.9 \mathrm{~kg} / \mathrm{m}^{2}\right)$ or over-nutrition $\left(\geq 25 \mathrm{~kg} / \mathrm{m}^{2}\right)$. Multivariate-adjusted odds ratios (aOR) were used to assess factors associated with undernutrition and over-nutrition.

Results: Of 1,242 HIV-positive adults interviewed, 849 (69\%) were female and median age was 41 years (IQR, 34-49). The majority (93\%) were on ART with a median treatment duration of 3 years (IQR, 1.1-4.3) and 581 (56\%) had advanced HIV disease and a median CD4 cell count of 348 cells/uL (IQR, 174-510) at their last scheduled visit. There were 776 (63.6\%) who had a normal BMI, 122 (10\%) who had under-nutrition (1.4\%-severe; 1.5\%-moderate; 7.1\%-mild) and 322 (26.4\%) who had over-nutrition (18.4\%-overweight; 8\%-obesity). Females and those of older age (35-44 years and $\geq 45$ years) versus 15-24 years were less likely to have undernutrition. Those reporting difficulty in accessing food in the past month $[\mathrm{aOR}=1.67(95 \% \mathrm{Cl}, 1.10-2.55)]$ and who had advanced HIV disease $[\mathrm{aOR}=2.25(95 \% \mathrm{Cl}, 1.34-3.77)]$ were more likely to have undernutrition. Being overweight or obese was more likely in females $[\mathrm{aOR}=3.86$ $(95 \% \mathrm{Cl}, 2.72-5.48)]$, in those age $\geq 45$ years $[\mathrm{aOR}=2.24(95 \% \mathrm{Cl}, 1.01-5.04)]$, those with higher wealth quintile and those with CD4 $>350$ cells/mL[aOR $=4.85(95 \% \mathrm{Cl}, 1.03-22.77)]$.

Conclusion: Zimbabwe faces two types of nutritional disorders; undernutrition and overweight / obesity, in its HIV-infected population, both of which are associated with increased morbidity and mortality. This may reflect a shift in the pattern of HIV/AIDS from being a highly fatal infectious disease to a chronic manageable condition.

Keywords: HIV, Malnutrition, Zimbabwe, Operational research

\footnotetext{
* Correspondence: ktakarinda@theunion.org

${ }^{1}$ AIDS \& TB Department, Ministry of Health and Child Care, P. O Box CY 1122, Causeway, Harare, Zimbabwe

${ }^{2}$ International Union Against Tuberculosis and Lung Disease, Paris, France

Full list of author information is available at the end of the article
}

(c) The Author(s). 2017 Open Access This article is distributed under the terms of the Creative Commons Attribution 4.0 International License (http://creativecommons.org/licenses/by/4.0/), which permits unrestricted use, distribution, and reproduction in any medium, provided you give appropriate credit to the original author(s) and the source, provide a link to the Creative Commons license, and indicate if changes were made. The Creative Commons Public Domain Dedication waiver (http://creativecommons.org/publicdomain/zero/1.0/) applies to the data made available in this article, unless otherwise stated. 


\section{Background}

There is increasing interest globally about malnutrition which directly affects one in three people living in the world [1], and refers to both undernutrition and overnutrition [2]. Malnutrition and dietary factors are important risk factors for the global burden of diseases such as diabetes [3], cardiovascular disease [4], and tuberculosis [5, 6]. According to the 2016 Global Nutrition report, the economic consequences of malnutrition represent losses of $11 \%$ of Gross Domestic Product (GDP) every year in Africa and Asia, whereas preventing malnutrition delivers US\$16 in returns on investment for every US\$1 spent [1].

Sub-Saharan Africa in particular has the highest prevalence estimates of undernourishment in the world, with $23.2 \%$ of its population affected [7]. Likewise, the region has the highest burden of Human Immunodeficiency Virus (HIV) infection, constituting 69\% of the estimated 36.7 million people living with HIV globally in 2015 [8]. HIV infection results in functionally defective metabolic ability at the individual level to absorb, store and utilize nutrients thus resulting in nutrient deficiencies, compromised immunity and increased risk of acquiring infectious diseases [9]. Insufficient food intake, together or with malabsorption, result in further progression of HIV-disease [10], and the subsequent weight loss and severe malnutrition that ensue are significant predictors of Acquired Immune Deficiency Syndrome (AIDS) related morbidity and mortality [11]. Despite the high global burden of HIV/AIDS, between 2010 and 2015 there has been more than a two-fold increase in the number of HIV-positive people receiving antiretroviral therapy (ART), which reached 10.3 million in eastern and southern Africa, the world's most affected regions. The scale up of ART has resulted in AIDS-related deaths in the region decreasing by 36\% since 2010 . While this is good news, there are certain factors associated with poor outcomes. For example, in subSaharan Africa, malnutrition in the form of low body mass index (BMI) is common at ART initiation ranging from $10 \%$ to $33 \%$ [12-15] and this is associated with poor treatment outcomes and increased mortality [13, 16].

Zimbabwe is one of the sub Saharan countries worst affected by the HIV epidemic with an HIV prevalence of $14.7 \%$ (14.66-14.71\%) among adults aged 15-49 years according to the 2015 national HIV estimates [17]. This translates to an estimated 1.4 million people aged 15 years and older living with HIV, although as of December 2015, only 788,000 (56\%) were enrolled on ART (source = National ART Programme). Zimbabwe's gross domestic product per capita in 2015 was US\$924,10 compared to US $\$ 1,588.50$ for the whole sub-Saharan Africa region [18]. Currently there is inadequate information on malnutrition prevalence among people living with HIV (PLHIV) in Zimbabwe and anecdotal evidence also suggests that nutritional assessment, care and support for PLHIV are weak. In line with Ministry of Health and Child Care in Zimbabwe (MoHCC) priorities, nutrition in people living HIV is a priority under the focal area of care, treatment and mitigation in the Zimbabwe National HIV/ AIDS Strategic Plan (ZNASP) II 2011-2015 document. The MoHCC therefore commissioned a study to better understand the interactions between HIV and nutrition in the country. The study was aimed at determining i) prevalence of malnutrition and ii) factors associated with both undernutrition and over-nutrition among PLHIV enrolled at ART clinics in Zimbabwe.

\section{Methods}

Study design

A nationally representative analytical cross-sectional study design was used.

\section{Study participants and sampling}

A list of 792 health facilities providing HIV treatment and care services inclusive of ART as of $31^{\text {st }}$ December 2012 was used as the sampling frame for this study. In order to keep the study logistically and financially feasible, sites which had supported less than 400 HIV-positive patients through HIV treatment and care services by $31^{\text {st }}$ December 2012 were excluded from the sampling frame. Of the remaining 235 health facilities providing HIV treatment and care services to $\geq 400$ patients, a total of 31 health facilities were sampled using a probability proportional to size (PPS) sampling criterion [19]. The PPS sampling was done to ensure sampling of a range of ART sites that are representative of Zimbabwe whilst taking into account all the 10 geographical regions. The minimum required sample size of $\mathrm{HIV}$-positive clients enrolled in ART clinics regardless of age was 1,420 assuming that the prevalence of malnutrition among adult PLHIV was $10.3 \%$ [12], without using a population correction factor, and using a design effect of 2, a $95 \%$ confidence interval, a $2.5 \%$ margin of error and assuming a response rate of $80 \%$.

Confirmed HIV-positive individuals who were enrolled in HIV treatment and care at the selected health facilities providing ART services were targeted for this survey. Overall there were 1,527 study respondents, however this paper focused only on the 1,242 participants aged $\geq 15$ years and consisted of non-pregnant women and men. This excluded 285 participants who consisted of pregnant/lactating women and children $<15$ years and were reserved for a separate paper. Patients who had attended the health facility for their scheduled HIV treatment and care appointment visit 
were recruited and interviewed prior to or after being attended to by a health worker. Voluntary written consent was sought from those aged $\geq 18$ years old whilst those aged 15-17 years were interviewed after obtaining parental assent if they were in the company of their parent or legal guardian.

\section{HIV treatment and care services at health facility level}

Once patients test HIV-positive in Zimbabwe, they are referred to a health facility that provides HIV treatment and care services. Patients are retested to confirm their HIV-positive status and are immediately registered in the pre-ART register. They are assigned a unique ART number and an individual ART care booklet. Adult patients (aged $\geq 15$ years old) are also assessed for ART eligibility currently based on having World Health Organisation (WHO) clinical staging III or IV or having a CD4 cell count $<500$ cells $/ \mathrm{mL}$ whilst all HIV-positive pregnant women since the end of 2013 are started on lifelong ART under Option B+ regardless of their CD4 cell count or WHO clinical staging. TB/HIV co-infected patients and those with chronic Hepatitis B are also initiated regardless of clinical or immunological status. Since the inception of the ART programme, the ART initiation criterion among adults has shifted from a CD4 cell count threshold of $<200$ cells $/ \mathrm{mL}$, to $<350$ cells $/ \mathrm{mL}$ from 2011 to 2013 and eventually to $<500$ cells $/ \mathrm{mL}$ from 2014 onwards in tandem with WHO guidelines [20-22]. ART regimens have become simpler and more efficacious over the years, moving from stavudine + lamivudine + nevirapine in the first 6 years of the ART progamme since 2004 to tenofovir + lamuvidine + nevirapine, and as of 2013, to tenofovir + lamuvidine + efavirenz which is administered as a single, fixed-dose combination pill to be taken once daily.

In pre-ART care, patients are provided with cotrimoxazole prophylaxis (CPT). A patient is seen every 2 weeks for the first month after initiating ART, and then monthly for the next few months in order to assess treatment adherence, inter-current illnesses, adverse drug events, or immune reconstitution syndrome. If patients are stable after the initial 6 months, they are seen 6 monthly thereafter for clinical consultations. Recommended clinical indices assessed at every visit include patient weight, WHO clinical stage, screening of comorbidities such as TB, and ART and CPT adherence assessment through pill counts and self-reporting by patients. Other than prior to ART initiation, laboratory indices such as complete blood count $(\mathrm{CBC})$ and CD4 counts should be done six monthly whilst serum alanine transaminase (ALT), serum creatinine, and of late in some regions viral load counts are conducted every 12 months.

\section{Data variables and data collection}

A three-day training workshop on familiarizing and pilot-testing the data collection tools and procedures was conducted prior to data collection. Data collectors consisted of health workers with prior experience of enumeration in other health-related surveys. Data collection was conducted between June and July of 2014 at all 31 selected ART clinics using an interviewer-administered questionnaire with coded responses. Questionnaires were also translated into the 2 main local languages (Shona and Ndebele) for respondents who were not conversant with English.

Variables collected included:- age, sex, educational level, rural/urban residence, history of TB treatment, the type of food consumed in the patient's household in the 7 days prior to the interview and household demographics such as number of household members, household assets and livestock and household income. Information on clinical characteristics such as CD4 cell count, WHO clinical staging, ART start date, and ART adherence was obtained from the individual patient care booklets for the interviewed patients. Weight and height measurements for the study respondents were measured and recorded at the start of the interview.

\section{Study definitions}

The main study outcome, nutritional status was based on body mass index (BMI) and calculated as weight in kilograms divided by height squared $\left(\mathrm{kg} / \mathrm{m}^{2}\right)$ and categorized as undernutrition (severe- $<16 \mathrm{~kg} / \mathrm{m}^{2}$; moderate16.0 to $16.99 \mathrm{~kg} / \mathrm{m}^{2}$ and mild-17.0 to $18.49 \mathrm{~kg} / \mathrm{m}^{2}$ ) and over-nutrition (overweight - 25.0 to $29.9 \mathrm{~kg} / \mathrm{m}^{2}$ and obesity- $\geq 30 \mathrm{~kg} / \mathrm{m}^{2}$ ) [23]. The wealth index, used in the survey and adopted from Filmer and Pritchett [24], was based on information collected from respondents on several items that measure household ownership of consumer durables which tend to be correlated with household wealth status, and these were used to quantify differences in household economic status. This wealth index variable was a continuous variable which was divided into 5 equal quintiles which were ranked from the lowest category (termed 'poorest quintile') to the highest category (termed 'richest quintile'). Food consumption score (FCS) which is a composite score based on dietary diversity, food frequency, and relative nutritional importance of different food groups was categorized as poor (0-21.4), borderline (21.5-35) and acceptable (>35) [25].

Having a household with income below US\$101.25/ person per month was categorized as having income below the Zimbabwe poverty datum line (PDL) for 2014 [26]. Likewise having household minimum consumption expenditure for food below US\$31.52/person per month, which is necessary to ensure that each household member can consume a minimum food 
basket representing 2,100 cal was defined as household income below the national food poverty line (FPL) for 2014 [26].

\section{Statistical analysis}

Patient data collected in the questionnaires were coded and single entered by 7 data entry clerks into EpiData (version 3.1; EpiData Association, Odense, Denmark) and later cleaned for errors and analyzed using Stata/SE 13.0 (Stata Corp, 2013, Stata Statistical Software: Release 13.0, College Station, TX). Prior to statistical analysis, data were weighted using proportional weights, in order to account for unequal probabilities of selection in the sampling and also to account for the complex design of the survey (i.e., stratification and clustering). Percentages and frequencies were generated for categorical variables while means (standard deviations) or alternatively medians (inter-quartile ranges (IQR)) were calculated for continuous variables as deemed appropriate.

Associations between the primary outcome measures (undernutrition and over-nutrition) with sociodemographic, food security and vulnerability variables and clinical characteristics were determined using the Pearson's chi-squared test or alternatively Fischer's Exact test. Univariate and multivariate-adjusted odds ratios $(\mathrm{aOR})$ and their respective $95 \%$ confidence intervals (CI) were calculated to determine factors associated with undernutrition and over-nutrition. Explanatory variables that were included in the multi-variate logistic regression models were those that had $p$-values $\leq 0.25$ in bi-variate analysis with the outcome measures. $P$-values $<0.05$ were considered as statistically significant.

\section{Results}

Table 1 shows the socio-demographic characteristics of the 1,242 HIV-positive adults who were enrolled in this study. There were 849 (68\%) females and the overall median age of all participants was 41 years (IQR, 34-49). Slightly more study participants resided in the rural areas $(n=699,56 \%)$ compared to urban areas $(n=543$, $44 \%)$. The majority of respondents had attained secondary school education $(n=662,57 \%)$ as their highest level of education while 467 (40\%) had attained primary school education.

Table 2 shows food security and vulnerability characteristics among study respondents. Only 32 (3\%) respondents had a poor household food consumption score whilst $261(21 \%)$ had a borderline household food consumption score. Slightly over ten percent of respondents reported having previously received food aid whilst 389 (31\%) reported having experienced difficulty in accessing food in the month preceding the survey. Approximately nine in ten respondents had a
Table 1 Socio-demographic characteristics among HIV-positive adults enrolled in ART clinics in Zimbabwe

\begin{tabular}{|c|c|c|c|c|}
\hline Characteristic & $n$ & $\mathrm{~N}$ & $\%$ & $(95 \% \mathrm{Cl})$ \\
\hline \multicolumn{5}{|l|}{ Area } \\
\hline Urban & 543 & 1,242 & 43.7 & $(43.4-48.4)$ \\
\hline Rural & 699 & 1,242 & 56.3 & $(51.6-56.6)$ \\
\hline \multicolumn{5}{|l|}{ Sex } \\
\hline Male & 393 & 1,242 & 31.6 & $(29.1-34.3)$ \\
\hline Female & 849 & 1,242 & 68.4 & $(65.7-70.9)$ \\
\hline \multicolumn{5}{|l|}{ Age in Years } \\
\hline $15-24$ & 51 & 1,242 & 4.1 & $(3.1-5.4)$ \\
\hline $25-34$ & 288 & 1,242 & 23.2 & (20.9-25.6) \\
\hline $35-44$ & 464 & 1,242 & 37.4 & $(34.7-40.1)$ \\
\hline $45-54$ & 265 & 1,242 & 21.3 & $(19.1-23.7)$ \\
\hline$>=55$ & 174 & 1,242 & 14.0 & $(12.2-16.1)$ \\
\hline Median (IQR) & & 1,242 & $41(34 ; 49)$ & \\
\hline \multicolumn{5}{|l|}{ Education Level } \\
\hline Primary & 467 & 1,159 & 40.3 & (37.5-43.2) \\
\hline Secondary & 662 & 1,159 & 57.1 & $(54.2-59.9)$ \\
\hline Higher & 30 & 1,159 & 2.6 & $(1.8-3.7)$ \\
\hline Missing & 83 & 1,242 & 6.7 & - \\
\hline \multicolumn{5}{|l|}{ Wealth quintile } \\
\hline Lowest & 251 & 1,242 & 20.2 & $(18.1-22.5)$ \\
\hline Second & 252 & 1,242 & 20.3 & (18.1-22.6) \\
\hline Middle & 243 & 1,242 & 19.6 & $(17.4-21.9)$ \\
\hline Fourth & 235 & 1,242 & 18.9 & $(16.8-21.2)$ \\
\hline Highest & 261 & 1,242 & 21.0 & $(18.8-23.4)$ \\
\hline
\end{tabular}

HIV Human Immunodeficiency virus, ART antiretroviral therapy, IQR interquartile range

household income below the poverty datum line and the food poverty line.

Clinical characteristics among HIV-positive adults enrolled in the study are shown in Table 3.

As shown in Table 3, the majority of respondents $(n$ $=1,152,93 \%$ ) were on ART and their median duration on treatment was 3 years (IQR, 1.1-4.3). Self-reported adherence to ART in the month preceding the survey was high with 1,056 (93\%) reporting adherence $\geq 95 \%$. Nearly a third of respondents reported a history of TB treatment whilst 165 (13\%) reported experiencing diarrhoea in the two weeks prior to the survey. Slightly more than half of the study respondents (56\%) were documented with an illness characterised by WHO clinical stage 3 or 4 at the most recent visit. Only 349 (28\%) study participants had a CD4 cell count measurement taken within six months of the interview date, and of these patients, the median CD4 cell count was 348 cells/mL (IQR, 174-510). 
Table 2 Food security and vulnerability characteristics among HIV-positive adults enrolled in ART clinics in Zimbabwe

\begin{tabular}{|c|c|c|c|c|}
\hline Characteristic & $\mathrm{n}$ & $\mathrm{N}$ & $\%$ & $(95 \% \mathrm{Cl})$ \\
\hline \multicolumn{5}{|c|}{ Household Food consumption score } \\
\hline Poor (0-21.4) & 32 & 1,242 & 2.6 & $(1.8-3.6)$ \\
\hline Borderline (21.5-35) & 261 & 1,242 & 21.0 & $(18.8-23.4)$ \\
\hline Acceptable (>35) & 949 & 1,242 & 76.4 & $(74.0-78.7)$ \\
\hline \multicolumn{5}{|l|}{ Received Food aid } \\
\hline No & 1,100 & 1,242 & 88.6 & $(86.7-90.2)$ \\
\hline Yes & 142 & 1,242 & 11.4 & $(9.8-13.3)$ \\
\hline \multicolumn{5}{|c|}{ Had difficulty accessing food in the past 30 days } \\
\hline No & 853 & 1,242 & 68.7 & $(66.0-71.2)$ \\
\hline Yes & 389 & 1,242 & 31.3 & $(28.8-34.0)$ \\
\hline \multicolumn{5}{|c|}{ Household Income compared to PDL } \\
\hline above PDL & 135 & 1,074 & 12.6 & $(10.7-14.7)$ \\
\hline Below PDL & 939 & 1,074 & 87.4 & $(85.3-89.3)$ \\
\hline Missing & 168 & 1,242 & 13.5 & - \\
\hline \multicolumn{5}{|c|}{ Household Income compared to FPL } \\
\hline above FPL & 102 & 1,240 & 8.2 & $(6.8-9.9)$ \\
\hline below FPL & 1,138 & 1,240 & 91.8 & $(90.1-93.2)$ \\
\hline Missing & 2 & 1,242 & 0.2 & - \\
\hline
\end{tabular}

HIV Human Immunodeficiency Virus, ART antiretroviral therapy, PDL poverty datum line, $F D L$ food poverty line

The nutritional status according to BMI among enrolled study patients is shown in Fig. 1. The mean BMI for all HIV-positive patients was $23.5 \mathrm{~kg} / \mathrm{m}^{2}$ (standard deviation 9.4). The majority ( $n=776,63.6 \%)$ had a normal BMI, 122 (10\%) had under nutrition which was severe in 17 (1.4\%), moderate in 18 (1.5\%) and mild in 87 (7.1\%). There were 224 (18.4\%) who were overweight and 98 (8\%) with obesity: thus overall $26 \%$ of all respondents were classified with overnutrition.

\section{Factors associated with undernutrition}

Factors associated with under-nutrition among enrolled study participants are shown in Table 4 . Females when compared to males were less likely to have undernutrition $[\mathrm{aOR}=0.31(95 \% \mathrm{CI}, 0.20-0.47)]$. Compared to 15 24 year olds, those of older age were also less likely to have undernutrition; 35-44 years $[\mathrm{aOR}=0.33(95 \% \mathrm{CI}$, $0.14-0.76)]$ and $\geq 45$ years $[\mathrm{aOR}=0.43(95 \% \mathrm{CI}, 0.19-$ 0.99)]. Those reporting difficulty in accessing food in the month prior to the survey had a higher likelihood of undernutrition $[\mathrm{aOR}=1.67(95 \% \mathrm{CI}, 1.10-2.55)]$. Having WHO clinical stage 3 or 4 was associated with a twofold higher odds of having undernutrition $[\mathrm{aOR}=2.25$ (95\% CI, 1.34-3.77)]. No significant differences were noted in risk factors for undernutrition when stratified by rural/urban residence.
Table 3 Clinical characteristics among HIV-positive adults enrolled in ART clinics in Zimbabwe

\begin{tabular}{|c|c|c|c|c|}
\hline Characteristic & $\mathrm{n}$ & $\mathrm{N}$ & $\%$ & $(95 \% \mathrm{Cl})$ \\
\hline \multicolumn{5}{|c|}{ Experienced diarrhoea in the past 2 weeks } \\
\hline No & 1,077 & 1,242 & 86.7 & $(84.7-88.5)$ \\
\hline Yes & 165 & 1,242 & 13.3 & $(11.5-15.3)$ \\
\hline \multicolumn{5}{|l|}{ ART status } \\
\hline No & 90 & 1,242 & 7.3 & $(5.9-8.8)$ \\
\hline Yes & 1,152 & 1,242 & 92.8 & $(91.2-94.1)$ \\
\hline \multicolumn{5}{|c|}{ Duration on ART in years } \\
\hline$<1$ & 248 & 1,152 & 21.5 & $(19.2-24.0)$ \\
\hline $1-2$ & 306 & 1,152 & 26.6 & $(24.1-29.2)$ \\
\hline $3-4$ & 339 & 1,152 & 29.4 & $(26.9-32.1)$ \\
\hline $5-6$ & 168 & 1,152 & 14.6 & $(12.7-16.7)$ \\
\hline$>6$ & 91 & 1,152 & 7.9 & $(6.5-9.6)$ \\
\hline Median & & 1,152 & $3(1.1-4.3)$ & \\
\hline
\end{tabular}

ART adherence in the past month

$\begin{array}{lllll}<95 \% & 83 & 1,139 & 7.3 & (5.9-9.0) \\ \geq 95 \% & 1,056 & 1,139 & 92.7 & (91.0-94.1) \\ \text { Missing } & 13 & 1,152 & 1.1 & - \\ \text { History of TB treatment } & & & \\ \text { No } & 894 & 1,238 & 72.2 & (69.6-74.6) \\ \text { Yes } & 344 & 1,238 & 27.8 & (25.4-30.4) \\ \text { Missing } & 4 & 1,242 & 0.3 & -\end{array}$

\section{Current WHO stage}

$\begin{array}{lllll}\text { I/I } & 464 & 1,045 & 44.4 & (41.4-47.4) \\ \text { III/IV } & 581 & 1,045 & 55.6 & (52.6-58.6) \\ \text { Missing } & 197 & 1,242 & 15.9 & -\end{array}$

Current CD4 cell count ${ }^{\mathrm{a}}$

$\begin{array}{lllll}\leq 50 & 26 & 349 & 7.5 & (5.1-10.7) \\ 51-200 & 75 & 349 & 21.5 & (17.5-26.1) \\ 201-350 & 75 & 349 & 21.5 & (17.5-26.1) \\ 351-500 & 78 & 349 & 22.4 & (18.3-27.0) \\ >500 & 95 & 349 & 27.2 & (22.8-32.2) \\ \text { Missing } & 893 & 1,242 & 71.9 & - \\ \quad \text { Median (IQR) } & & 349 & 348(174-510) & \end{array}$

HIV Human Immunodeficiency Virus, ART antiretroviral therapy, IQR interquartile range, $W H O$ World Health Organization

${ }^{a}$ Current CD4 cell count was taken as a CD4 cell count obtained with

6 months from date of data collection

\section{Factors associated with over-nutrition}

Table 5 shows factors associated with over-nutrition among enrolled HIV-positive study participants in ART clinics in Zimbabwe. Females when compared to males were nearly four times more likely to have over-nutrition $[\mathrm{aOR}=3.86$ (95\% CI, 2.72-5.48)]. Over-nutrition was also higher among those aged $\geq 45$ years $[\mathrm{aOR}=2.24$ (95\% CI, 1.01-5.04)] in comparison to those aged 15-24 


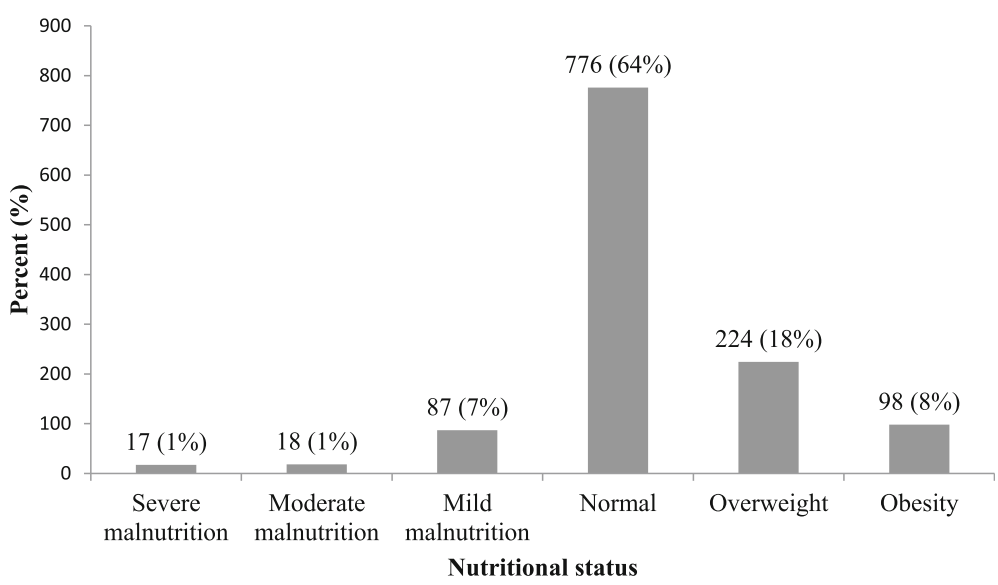

Fig. 1 Nutritional status among HIV-positive adults enrolled in ART clinics in Zimbabwe. SAM = severe acute malnutrition; MAM= moderate acute malnutrition; HIV = Human Immunodeficiency Virus; ART = antiretroviral therapy

years old. The odds of having over-nutrition also increased with higher wealth quintile [highest versus lowest quintile $-\mathrm{aOR}=2.84(95 \% \mathrm{CI}, 1.66-4.86)]$ and with increasing CD4 cell count of $\mathrm{CD} 4>350$ cells $/ \mathrm{mL}$ [aOR $=4.85(95 \% \mathrm{CI}, 1.03-22.77)]$.

Multivariate regression for risk factors associated with over-nutrition was also carried out when stratified by rural/urban residence (data are not shown). The odds of over-nutrition increased with higher wealth quintile for urban dwellers only [highest versus lowest quintile $\mathrm{aOR}=3.39(95 \% \mathrm{CI}, 1.52-7.56)]$ whilst no differences were noted for rural dwellers. For rural dwellers, difficulty in accessing food in the past 30 days was associated with a lower odds of over-nutrition $[\mathrm{aOR}=0.33(95 \% \mathrm{CI}, 0.15$ $0.74)]$ whilst no differences were noted for urban dwellers.

\section{Discussion}

This is the first nationally representative study in Zimbabwe conducted among HIV-positive patients enrolled in HIV treatment and care settings and aimed at determining prevalence of malnutrition and associated factors. Our study findings show that there is a high burden of malnutrition with about two in five of all HIV-positive patients being affected. Of note, the problem of malnutrition is a double-edged sword with both over-nutrition and undernutrition being prevalent in this population. Over-nutrition affected approximately a quarter of all patients in comparison to under-nutrition which affected only a tenth of all HIV-positive patients. We also observed that undernutrition was more prevalent among males compared to females, among older adolescents and young adults, among those who encountered difficulty accessing food in the past month and those with advanced HIV disease. We also observed that over-nutrition was higher among females, in the older age groups and also increased with higher wealth quintile and increasing $\mathrm{CD} 4$ cell count.
The strengths of this study include a large sample and the use of PPS sampling which ensured that our findings are nationally representative of HIV-positive patients enrolled in HIV treatment and care settings in Zimbabwe. The weight of study participants was measured using standardized and calibrated weight scales whilst height was measured using standardized height boards thus ensuring the body mass indices for these patients were current, accurate and comparable. A standardized questionnaire was also administered by trained data collectors and this ensured that all study participants were comparable. Study limitations may have included the possibility of recall bias by study respondents on the type of foods consumed in their households in the week preceding the survey and the frequency of their consumption. This may have led to incorrect calculation and misclassification of the household food consumption score. This study may not be representative of those HIV-positive patients who were enrolled in HIV treatment and care settings but missed their scheduled clinic review visits because they were too sick to attend the clinic. Whilst data were collected for pregnant and lactating women and those aged $<15$ years old, these were excluded from the analysis of nutritional status since their numbers were too small to allow meaningful inferences and also because body mass index is not an appropriate measure of nutritional status in pregnant and lactating women. Lastly, the use of BMI may underestimate the prevalence of obesity since it is reported to have low sensitivity and can miss a proportion of adults with excess body adiposity $[27,28]$.

In this study we observed that undernutrition was less common when compared to over-nutrition among HIVpositive adults enrolled in ART clinics in Zimbabwe. This is in sharp contrast to other studies in the African region where malnutrition $\left(\mathrm{BMI}<18.5 \mathrm{~kg} / \mathrm{m}^{2}\right)$ was more 
Table 4 Factors associated with under-nutrition among HIVpositive adults enrolled in ART clinics in Zimbabwe

\begin{tabular}{llll}
\hline Characteristic & $\mathrm{n}(\%)$ & $\mathrm{OR}(95 \% \mathrm{Cl})$ & $\mathrm{aOR}(95 \% \mathrm{Cl})$ \\
\hline $\begin{array}{llll}\text { Area } \\
\text { Urban }\end{array}$ & $58(11.0)$ & reference & reference \\
$\begin{array}{l}\text { Rural } \\
\text { Sex }\end{array}$ & $64(9.2)$ & $0.82(0.56 ; 1.19)$ & $0.87(0.57 ; 1.32)$ \\
Male & $66(17.1)$ & reference & reference \\
Female & $56(6.7)$ & $\mathbf{0 . 3 5}(\mathbf{0 . 2 4} \mathbf{0 . 5 1 )}$ & $\mathbf{0 . 3 1} \mathbf{( 0 . 2 0 ; 0 . 4 7 )}$ \\
Age in years & & & \\
$15-24$ & $10(20.4)$ & reference & reference \\
$25-34$ & $29(10.4)$ & $0.45(0.2 ; 1)$ & $0.50(0.21 ; 1.20)$ \\
$35-44$ & $37(8.0)$ & $\mathbf{0 . 3 4}(\mathbf{0 . 1 6} \mathbf{0 . 7 4 )}$ & $\mathbf{0 . 3 4}(\mathbf{0 . 1 5} \mathbf{0 . 8 0})$ \\
$45-54$ & $46(10.7)$ & $0.47(0.22 ; 1.02)$ & $\mathbf{0 . 4 3} \mathbf{( 0 . 1 9 ; 0 . 9 9 )}$
\end{tabular}

Received Food aid

$\begin{array}{llll}\text { No } & 102(9.5) & \text { reference } & \text { reference } \\ \text { Yes } & 20(14.1) & 1.57(0.94 ; 2.63) & 1.36(0.77 ; 2.39)\end{array}$

Had difficulty accessing food in the past 30 days

$\begin{array}{llll}\text { No } & 72(8.6) & \text { reference } & \text { reference } \\ \text { Yes } & 50(13.0) & \mathbf{1 . 5 9}(\mathbf{1 . 0 8 ;} \mathbf{2 . 3 3}) & \mathbf{1 . 6 7}(\mathbf{1 . 1 0 ;} \mathbf{2 . 5 5})\end{array}$

Experienced diarrhoea in the past 2 weeks

$\begin{array}{llll}\text { No } & 97(9.2) & \text { Reference } & \text { reference } \\ \text { Yes } & 25(15.6) & \mathbf{1 . 8 4}(\mathbf{1 . 1 4} ; \mathbf{2 . 9 6}) & 1.49(0.89 ; 2.52)\end{array}$

ART status and duration in years

$\begin{array}{llll}\text { Pre-ART } & 11(12.5) & \text { Reference } & \text { reference } \\ <1 & 33(13.5) & 1.09(0.53 ; 2.27) & 0.75(0.41 ; 1.39) \\ 1-2 & 28(9.3) & 0.72(0.34 ; 1.51) & 0.65(0.34 ; 1.21) \\ 3-4 & 27(8.1) & 0.62(0.29 ; 1.3) & 0.74(0.36 ; 1.54) \\ 5-6 & 16(9.9) & 0.77(0.34 ; 1.73) & 0.56(0.21 ; 1.45) \\ >6 & 7(7.7) & 0.58(0.22 ; 1.58) & 1.26(0.57 ; 2.81)\end{array}$

History of TB treatment

\begin{tabular}{|c|c|c|c|}
\hline No & $75(8.5)$ & Reference & reference \\
\hline Yes & $47(13.9)$ & $1.74(1.18 ; 2.56)$ & $1.30(0.84 ; 2.01)$ \\
\hline
\end{tabular}

Current WHO stage

\begin{tabular}{|c|c|c|c|}
\hline |/II & $28(6.1)$ & Reference & reference \\
\hline III/IV & 72 (12.6) & $2.2(1.4 ; 3.47)$ & $2.25(1.34 ; 3.77)$ \\
\hline
\end{tabular}

Current CD4 cell count ${ }^{\mathrm{a}}$

\begin{tabular}{llll}
$\leq 50$ & $8(30.8)$ & reference & reference \\
$51-200$ & $10(13.5)$ & $0.35(0.12 ; 1.02)$ & $0.47(0.14 ; 1.51)$ \\
$201-350$ & $8(11.0)$ & $\mathbf{0 . 2 8}(\mathbf{0 . 0 9} \mathbf{0 . 8 4})$ & $0.43(0.13 ; 1.45)$ \\
$\geq 350$ & $18(10.4)$ & $\mathbf{0 . 2 6}(\mathbf{0 . 1 0} \mathbf{0 . 6 9 )}$ & $0.53(0.18 ; 1.56)$ \\
\hline
\end{tabular}

OR odds ratio, $a O R$ multivariate-adjusted odds ratio, $\mathrm{Cl}$ confidence interval, $\mathrm{HIV}$ Human Immunodeficiency Virus, ART antiretroviral therapy, TB Tuberculosis, WHO World Health Organization

${ }^{a}$ Current CD4 cell count was taken as a CD4 cell count obtained with 6 months from date of data collection

NB: All odds ratios and $95 \%$ confidence intervals in bold font are statistically significant with $\mathrm{p}$-values $<0.05$ common and as high as $26.3 \%$ [14] and 36\% [29]. In one meta-analysis published in 2015, malnutrition (BMI < $18.5 \mathrm{~kg} / \mathrm{m}^{2}$ ) was reported as one of the leading causes of hospital admission among HIV-positive adults in the Africa region [30]. Weight loss which leads to severe and moderate malnutrition is common in HIV infection and can be caused by low dietary intake due to loss of appetite, mouth ulcers, food insecurity and also due to malabsorption of macronutrients and an altered metabolism [31]. Men were more likely to have undernutrition compared to women, and we attribute this to the established fact that they present late for HIV treatment and care with advanced HIV disease and low CD4 counts in Zimbabwe [32] and other African settings [33, 34]. Lower CD4 cell counts have been found to be associated with severe and moderate malnutrition $[14,29]$ and these are also associated with increased mortality [35]. Similar to other studies, household food insecurity which affects the frequency of meals and dietary diversity of meals consumed in a household has been commonly reported as a predictor of poor nutritional status [36]. There were no differences in levels of undernutrition between PLHIV in rural and urban residences and this could be explained by our findings that show that study participants were generally from poor households given that the majority had household incomes below the national poverty datum line and food poverty line. Whilst urban dwellers may be perceived to have better food security and subsequently better nutritional status due to high economic activity, high levels of food insecurity and consequently malnutrition have been reported in Southern Africa and are related to rapid urbanization resulting in informal settlements [37].

In our sample, there were significantly higher proportions of HIV-positive patients who were overweight or obese compared with those at the other end of the scale. Our data also shows that the prevalence of being overweight and obese was slightly lower among HIV-positive women compared to women in the general population, with this data taken from women in the 2010-11 Zimbabwe Demographic and Health Survey (ZDHS) [38]. Interestingly, the population prevalence of women who were overweight or obese from this ZDHS (31\%) was higher than the pooled prevalence for the Sub-Saharan Africa region at $23 \%$ [38], and this could be related to the 2011 World Bank poverty headcount ratio at US\$1.90 which was $21 \%$ for Zimbabwe compared to $44 \%$ for subSaharan Africa [39]. Increasing CD4 cell count was found to be associated with being overweight and obese and this concurs with findings from a follow-up of 17 ART cohorts in North America with sustained viral suppression [40, 41]. With women being more likely to be overweight or obese relative to men, this may again be related to their earlier entry into HIV care and ART initiation with relatively 
Table 5 Factors associated with over-nutrition among HIVinfected adults enrolled in ART clinics in Zimbabwe

\begin{tabular}{|c|c|c|c|}
\hline Characteristic & $\mathrm{n}(\%)$ & OR $(95 \% \mathrm{Cl})$ & aOR (95\% Cl) \\
\hline \multicolumn{4}{|l|}{ Area } \\
\hline Urban & $163(31.0)$ & reference & reference \\
\hline Rural & $159(22.9)$ & $0.66(0.51-0.85)$ & $0.9(0.66-1.25)$ \\
\hline \multicolumn{4}{|l|}{ Sex } \\
\hline Male & $51(13.2)$ & reference & reference \\
\hline Female & $271(32.5)$ & $3.16(2.28-4.39)$ & $3.86(2.72-5.48)$ \\
\hline \multicolumn{4}{|l|}{ Age in years } \\
\hline $15-24$ & $9(18.4)$ & reference & reference \\
\hline $25-34$ & $70(25.1)$ & $1.49(0.69-3.22)$ & $1.48(0.65-3.36)$ \\
\hline $35-44$ & $118(25.6)$ & $1.53(0.72-3.25)$ & $1.60(0.72-3.56)$ \\
\hline$\geq 45$ & $125(29.0)$ & $1.82(0.86-3.85)$ & $2.24(1.01-5.04)$ \\
\hline \multicolumn{4}{|l|}{ Wealth quintile } \\
\hline Lowest & $36(14.5)$ & reference & reference \\
\hline Second & $65(25.9)$ & $2.06(1.31-3.23)$ & $2.07(1.29-3.33)$ \\
\hline Middle & $60(24.9)$ & $1.95(1.23-3.09)$ & $1.94(1.19-3.17)$ \\
\hline Fourth & 79 (34.5) & $3.10(1.99-4.85)$ & $3.15(1.91-5.18)$ \\
\hline Highest & $82(32.7)$ & $2.86(1.84-4.44)$ & $2.84(1.66-4.86)$ \\
\hline
\end{tabular}

Household Food consumption score

$\begin{array}{llll}\text { Poor (0-21) } & 7(24.1) & \text { reference } & \text { reference } \\ \text { Borderline } & 55 & 0.85 & 0.92 \\ (21.5-35) & (21.2) & (0.34-2.09) & (0.36-2.37) \\ \text { Acceptable }(>35) & 260(27.9) & 1.22(0.51-2.88) & 1.06(0.43-2.64) \\ \text { Had difficulty accessing food in the past 30 days } & \\ \text { No } & 229(27.4) & \text { reference } & \text { reference } \\ \text { Yes } & 93(24.2) & 0.85(0.64-1.12) & 0.85(0.62-1.16)\end{array}$

Household Income compared to PDL

$\begin{array}{llll}\text { above PDL } & 47(36.2) & \text { reference } & \text { reference } \\ \text { Below PDL } & 238(25.7) & \mathbf{0 . 6 1}(\mathbf{0 . 4 1 - 0 . 9 )} & 0.84(0.52-1.35)\end{array}$

Household Income compared to FPL

\begin{tabular}{|c|c|c|c|}
\hline above FPL & $40(40.4)$ & reference & reference \\
\hline below FPL & $282(25.2)$ & $0.5(0.32-0.76)$ & $0.52(0.31-0.87)$ \\
\hline \multicolumn{4}{|c|}{ Duration on ART in years } \\
\hline Pre-ART & $20(22.7)$ & reference & reference \\
\hline$<1$ & $57(23.4)$ & $1.13(0.76-1.67)$ & $0.92(0.59-1.45)$ \\
\hline $1-2$ & 77 (25.6) & $1.25(0.85-1.83)$ & $1.04(0.67-1.63)$ \\
\hline $3-4$ & $92(27.5)$ & $1.26(0.80-1.99)$ & $0.91(0.54-1.54)$ \\
\hline $5-6$ & $45(27.8)$ & $1.70(1.00-2.87)$ & $1.12(0.61-2.04)$ \\
\hline$>6$ & $31(34.1)$ & $0.96(0.54-1.72)$ & $0.85(0.45-1.59)$ \\
\hline
\end{tabular}

Current WHO stage

$\begin{array}{llll}\text { I/II } & 132(29.0) & \text { reference } & \text { reference } \\ \text { III/IV } & 143(25.0) & 0.82(0.62-1.08) & 0.89(0.65-1.20)\end{array}$

Table 5 Factors associated with over-nutrition among HIVinfected adults enrolled in ART clinics in Zimbabwe (Continued)

\begin{tabular}{|c|c|c|c|}
\hline \multicolumn{4}{|c|}{ Current CD4 cell count ${ }^{a}$} \\
\hline$\leq 50$ & $2(7.7)$ & reference & reference \\
\hline $51-200$ & $10(13.5)$ & $1.87(0.38-9.19)$ & $1.66(0.32-8.62)$ \\
\hline $201-350$ & $21(28.8)$ & $4.85(1.05-22.36)$ & $4.51(0.92-22.15)$ \\
\hline$>350$ & $58(33.5)$ & $6.05(1.38-26.5)$ & $4.85(1.03-22.77)$ \\
\hline
\end{tabular}

$O R$ odds ratio, $a O R$ multivariate-adjusted odds ratio, $\mathrm{Cl}$ confidence interval, HIV Human Immunodeficiency Virus, $A R T$ antiretroviral therapy, $P D L$ poverty datum line, FPL food poverty line, WHO World Health Organization

${ }^{a}$ Current CD4 cell count was taken as a CD4 cell count obtained with 6 months from date of data collection

NB: All odds ratios and $95 \%$ confidence intervals in bold font are statistically significant with $\mathrm{p}$-values $<0.05$

higher CD4 cell counts compared to men [40, 41]. In many African settings including Zimbabwe, women have better access than men to HIV testing and treatment services through integration of HIV testing services in antenatal care settings [42], which act as an entry point into preventionof-mother-to- child HIV transmission (PMTCT) services. Given that the majority of HIV-positive individuals enrolled in this study were on ART, there may also be a high prevalence of HIV-related lipodystrophy which has been reported, in one systematic review study, to develop within the first six months of therapy particularly with the use of stavudine [43]. Lipodystropy can predispose HIV-positive individuals to cardiovascular disease [44], and hence the need to evaluate its prevalence, pathogenesis and prognosis in order to inform clinical management given the rapid national scale-up of ART and the subsequent longer survival as HIV-related mortality continues to decline. However, the use of stavudine based antiretroviral regimens has been phased out since 2013 due to these adverse events.

In addition, metabolic complications such as dyslipidemia, insulin resistance, and diabetes mellitus are also common among obese patients with well-controlled HIVinfection who are on long-term ART. These complications are also associated with increased risk of cardiovascular disease. Metabolic complications probably develop due to traditional risk factors such as obesity or genetic predisposition and HIV-specific and ART-specific contributions including chronic inflammation and immune activation [45]. Study participants who were of a higher wealth index were more likely to be overweight and obese but this trend was observed only among the urban participants. Unlike rural dwellers, where food insecurity is an issue, this trend is likely to be due to urban dwellers having better food security, having access to more refined and unhealthy food diets and also having more sedentary lifestyles [46]. Other studies have also found people of higher socioeconomic and wealth status [38] to have a higher prevalence of obesity and they are more likely to develop or have hypertension and diabetes [47]. 
This study has a number of implications. First, there is a double burden of undernutrition and over-nutrition amongst the country's population of HIV-positive patients enrolled in ART clinics. It is therefore important that health workers routinely assess and document weight and height measurements in individual health facility records to enable BMI monitoring as a proxy measure of nutritional status. A previous nationally representative record review of ART treatment outcomes among HIV-positive patients enrolled in ART clinics in Zimbabwe showed that approximately a quarter of all patients did not have recorded weight at ART initiation and this must change and improve [40]. Low baseline weight at ART initiation has been shown to increase the risk of ART attrition from care and mortality $[40,48]$ and given its association with late presentation with advanced HIV, this points towards a need to encourage early seeking of HIV testing services and subsequent ART initiation. Currently, the national ART programme is shifting towards an HIV 'treat-all' approach which promotes earlier ART initiation with promising improved treatment outcomes.

Second, the addition of micronutrient supplements to ART may provide increased nutritional recovery among HIV-positive patients with undernutrition $[49,50]$ and also more importantly improve adherence to ART among foodinsecure adults as has been shown in Zambia [51] though no significant gains were observed with respect to weight and CD4 cell count response. However, despite improved health and ART adherence, perceptions among foodinsecure HIV-positive adults participating in one Kenyan food supplementation program highlighted the inevitability of sharing food disbursements with people outside their families thus depleting the food available for them [52]. Any adoption of food supplementation programmes in ART clinics will therefore need to take this into consideration so as to ensure that the targeted malnourished HIVpositive patients benefit from these interventions.

Third, with obesity becoming prevalent in the HIV population on ART, HIV may change from being a highly fatal infectious disease into a chronic manageable disease that is associated with an elevated risk of cardiovascular-related conditions such as diabetes mellitus and hypertension. This calls for an urgent need to integrate the screening and management of hypertension and diabetes mellitus into HIV clinics [53], and particularly among patients who are overweight and obese.

\section{Conclusion}

In conclusion, we have found that being overweight or obese is more prevalent than being underweight in HIVpositive patients enrolled in HIV treatment and care settings and on ART in Zimbabwe, and this is more common in females, in those of older age and in those with increasing wealth index. Given that over-nutrition predisposes patients to cardiovascular-related conditions, there is an urgent need to integrate into HIV treatment and care services the screening of hypertension and diabetes mellitus in order to enable these conditions to be identified and appropriately managed to prevent cardiovascular complications.

\section{Abbreviations}

AIDS: Acquired immunodeficiency syndrome; ALT: Serum alanine transaminase; aOR: Multivariate-adjusted odds ratios; ART: Antiretroviral therapy; BMI: Body mass index; CBC: Complete blood count; Cl: Confidence interval; CPT: Cotrimoxazole preventive therapy; EAG: Ethics Advisory Group; FCS: Food consumption score; FPL: Food poverty line; GDP: Gross domestic product; HIV: Human Immunodeficiency Virus; IQR: Interquartile range; IUATLD: International Union Against Tuberculosis \& Lung Disease; MoHCC: Ministry of Health and Child Care in Zimbabwe; MRCZ: Medical Research Council of Zimbabwe; PDL: Poverty datum line; PLHIV: People living with HIV; PMTCT: Prevention of mother-to-child transmission; PPS: Probability proportional to size; TB: Tuberculosis; WHO: World Health Organisation; ZDHS: Zimbabwe Demographic and Health Survey; ZNASP: Zimbabwe National HIV/AIDS Strategic Plan

\section{Funding}

Funding for the study was obtained from the World Food Programme Zimbabwe and The Global Fund HIV and AIDS grant in Zimbabwe. Technical support in writing this paper was provided through The International Union Against Tuberculosis and Lung Disease. KCT is supported as an operational research fellow from the Centre for Operational Research at The Union, Paris, France. We thank the Department for International Development (DFD), UK, for funding this open access publication.

\section{Availability of data and materials}

The data that support the findings of this study are available from the Ministry of Health and Child Care in Zimbabwe but restrictions apply to the availability of these data, which were used under license for the current study, and so are not publicly available. Data are however available from the authors upon reasonable request and with permission of Ministry of Health and Child Care in Zimbabwe.

\section{Authors' contributions}

$K C T, T M A, B N, A C, M M, M B, B M$ and $O M$ were involved in the design the study and data collection. KCT analysed data, wrote the first draft and subsequently coordinated the writing of the subsequent drafts and the final paper. $\mathrm{ADH}, \mathrm{TMA}, \mathrm{BN}, \mathrm{AC}, \mathrm{MM}, \mathrm{MB}, \mathrm{BM}$ and $\mathrm{OM}$ contributed to the review of all subsequent drafts of the paper. All authors read and approved the final paper.

\section{Competing interests}

The authors declare that they have no competing interests.

\section{Consent for publication}

Not applicable.

\section{Ethics approval and consent to participate}

Ethics approval for the study was obtained prior to data collection from the Medical Research Council of Zimbabwe (MRCZ) and also Ethics Advisory Group (EAG) for the International Union Against Tuberculosis and Lung Disease (IUATLD), Paris, France. Voluntary written consent was sought from those aged $\geq 18$ years old whilst those aged 15-17 years were interviewed after obtaining parental assent if they were in the company of their parent or legal guardian.

\section{Author details}

${ }^{1}$ AIDS \& TB Department, Ministry of Health and Child Care, P. O Box CY 1122, Causeway, Harare, Zimbabwe. ${ }^{2}$ International Union Against Tuberculosis and Lung Disease, Paris, France. ${ }^{3}$ Department of Family Health, Ministry of Health and Child Care, Harare, Zimbabwe. ${ }^{4}$ Department of Clinical Research, London School of Hygiene and Tropical Medicine, London, UK. 
Received: 19 September 2016 Accepted: 24 January 2017 Published online: 06 February 2017

\section{References}

1. International Food Policy Research Institute. Global Nutrition Report 2016: From Promise to Impact: Ending Malnutrition by 2030. Washington, DC: International Food Policy Research Institute; 2016.

2. Blössner M, De Onis M. Malnutrition: quantifying the health impact at national and local levels. Geneva: Environmental Burden Disease Series; 2005. doi:10.1371/journal.pone.0107040.

3. Mokdad A, Ford E, Bowman B, Dietz W, Vinicor F, Bales V, et al. Prevalence of obesity, diabetes, and obesity-related health risk factors, 2001. JAMA. 2003:289:76-9. doi:10.1001/jama.289.1.76.

4. Hubert H, Feinlieb M, McNamara P, Castelli W. Obesity as an Independent Risk Factor for Cardiovascular Disease: A 26-year Follow-up of Participants in the Framingham Heart Study. Circulation. 1983;67:968-77.

5. Koethe J, von Reyn C. Protein-calorie malnutrition, macronutrient supplements, and tuberculosis. Int J Tuberc Lung Dis. 2016;20:857-63. doi:10.5588/ijtld.15. 0936. Protein-calorie.

6. Anuradha R, Munisankar S, Bhootra Y, Kumar NP, Dolla C, Kumaran P, et al. Coexistent Malnutrition Is Associated with Perturbations in Systemic and Antigen-Specific Cytokine Responses in Latent Tuberculosis Infection. Clin Vaccine Immunol. 2016;23:339-45. doi:10.1128/CVI.00009-16.

7. FAO I and W. The State of Food Insecurity in the World 2015. Meeting the 2015 international hunger targets: taking stock of uneven progress. Rome: FAO I and W; 2015.

8. Joint United Nations Programme on HIV/AIDS (UNAIDS). Global AIDS Update 2016. Geneva: UNAIDS; 2016.

9. Katona P, Katona-Apte J. The Interaction between Nutrition and Infection. Clin Infect Dis. 2008:46:1582-8. doi:10.1086/587658.

10. Wheeler DA. Weight loss and disease progression in HIV infection. AIDS Read. 1999;9:347-53.

11. Melchior JC, Niyongabo T, Henzel D, Durack-Bown I, Henri SC, Boulier A. Malnutrition and wasting, immunodepression, and chronic inflammation as independent predictors of survival in HIV-infected patients. Nutrition. 1999; 15:865-9. doi:10.1016/S0899-9007(99)00210-5.

12. Uthman OA. Prevalence and pattern of HIV-related malnutrition among women in sub-Saharan Africa: a meta-analysis of demographic health surveys. BMC Public Heal Heal. 2008:8:226. doi:10.1186/1471-2458-8-226.

13. Weiser SD, Fernandes KA, Brandson EK, Lima VD, Anema A, Bangsberg DR, et al. The association between food insecurity and mortality among HIVinfected individuals on HAART. J Acquir Immune Defic Syndr. 2009;52:342-9. doi:10.1097/QAl.0b013e3181b627c2.The.

14. Benzekri N, Sambou J, Diaw B, El HS, Sall F, Niang A, et al. High prevalence of severe food insecurity and malnutrition among HIV-infected adults in Senegal, West Africa. PLoS One. 2015;10:e0141819. doi:10.1371/journal.pone. 0141819. eCollection 2015

15. Argemi X, Dara S, You S, Mattei JF, Courpotin C, Simon B, et al. Impact of malnutrition and social determinants on survival of HIV-infected adults starting antiretroviral therapy in resource-limited settings. AIDS. 2012;26: 1161-6. doi:10.1097/QAD.0b013e328353f363.

16. Koethe JR, Lukusa A, Giganti MJ, Chi BH, Nyirenda CK, Limbada MI, et al. Association between weight gain and clinical outcomes among malnourished adults initiating antiretroviral therapy in Lusaka, Zambia. J Acquir Immune Defic Syndr. 2010;53:507-13. doi:10.1097/QAI. 0b013e3181b32baf.

17. Zimbabwe Ministry of Health and Child Care. Zimbabwe National and Subnational HIV and AIDS Estimates 2014. Harare: Zimbabwe Ministry of Health and Child Care; 2014.

18. World Bank. Gross Domestic Product (GDP) per capita (current US\$) [Internet]. 2016. Available: http://data.worldbank.org/indicator/NY.GDP.PCAP. CD?end=2015\&locations=ZG\&start=1960. Accessed 12 Dec 2016.

19. Bierrenbach. Steps in applying Probability Proportional to Size (PPS) and calculating Basic Probability Weights [Internet]. pp. 1-5. Available: http:// www.who.int/tb/advisory_bodies/impact_measurement_taskforce/ meetings/prevalence_survey/psws_probability_prop_size_bierrenbach.pdf. Accessed 12 Dec 2016.

20. World Health Organisation (WHO). Consolidated Guidelines on the use of antiretroviral drugs for treating and preventing HIV infection: Recommendations for a public health approach June 2013 [Internet].
Geneva: WHO; 2013. Available: www.who.int/iris/bitstream/10665/85321/1/ 9789241505727_eng.pdf. Accessed 12 Dec 2016.

21. World Health Organisation (WHO). Antiretroviral therapy for HIV infection in adults and adolescents: recommendations for a public health approach. 2010 revision [Internet]. Geneva: WHO; 2010. Available: http://www.who.int/ hiv/pub/arv/adult2010/en/index.html. Accessed 12 Dec 2016.

22. World Health Organisation. Antiretroviral therapy for hiv infection in adults and adolescents: Recommendations for a public health approach - 2006 revision [Internet]. WHO, editor. World Health Organization. Geneva: WHO; 2006. Available: http://www.who.int/hiv/pub/guidelines/artadultguidelines. pdf. Accessed 12 Dec 2016.

23. Data D. BMI classification 1. WHO. Physical status: the use and interpretation of anthropometry. Report of a WHO Expert Committee. WHO Technical Report Series. 2002. p. 25-6.

24. Filmer D, Pritchett LH. Estimating Wealth Effects Without Expenditure Data — or Tears :An application to educational enrollments in states of India. Demography. 2001;38:115-32. doi:10.1353/dem.2001.0003.

25. World Food Programme. Food consumption analysis - calculation and use of the food consumption score in food security analysis [Internet]. Technical Guidance Sheet. Rome; 2008. doi:10.1017/CBO9781107415324.004

26. Zimbabwe National Statistics Agency (ZIMSTATS). Poverty Analysis - Overview [Internet]. World Bank. Harare; 2014. Available: http://www.zimstat.co.zw/ sites/default/files/img/publications/Prices/Poverty_04_2016.pdf. Accessed 12 Dec 2016

27. Romero-Corral A, Somers VK, Sierra-Johnson J, Thomas RJ, Collazo-Clavell $\mathrm{ML}$, Korinek J, et al. Accuracy of body mass index in diagnosing obesity in the adult general population. Int J Obes (Lond). 2008;32:959-66. doi:10.1038/ijo.2008.11.

28. Centers for Disease Control and Prevention. Body mass index: Considerations for practitioners. In: Cdc [Internet]. 2011 [cited 27 Jun 2016] pp. 1-4. Available: https://www.cdc.gov/obesity/downloads/BMlforPactitioners.pdf. Accessed 12 Dec 2016.

29. Sicotte M, Bemeur C, Diouf A, Zunzunegui MV, Nguyen V. Nutritional status of HIV-infected patients during the first year HAART in two West African cohorts. J Heal Popul Nutr. 2015;34. doi:10.1186/s41043-015-0001-5.

30. Ford N, Shubber Z, Meintjes G, Grinsztejn B, Eholie S, Mills EJ, et al. Causes of hospital admission among people living with HIV worldwide: a systematic review and meta-analysis. Lancet HIV. 2015;2:e438-44. doi:10.1016/S23523018(15)00137-X.

31. de Pee S, Semba RD. Role of nutrition in HIV infection: review of evidence for more effective programming in resource-limited settings. Food Nutr Bull. 2010;31:S313-44.

32. Takarinda KC, Harries AD, Shiraishi RW, Mutasa-Apollo T, Abdul-Quader A, Mugurungi $O$. Gender-related differences in outcomes and attrition on antiretroviral treatment among an HIV-infected patient cohort in Zimbabwe: 2007-2010. Int J Infect Dis International Society for Infectious Diseases. 2015:30:98-105. doi:10.1016/j.jijid.2014.11.009.

33. Agaba PA, Meloni ST, Sule HM, Agbaji OO, Ekeh PN, Job GC, et al. Patients who present late to HIV care and associated risk factors in Nigeria. HIV Med. 2014;15:396-405. doi:10.1111/hiv.12125.

34. Kwobah CM, Braitstein P, Koech JK, Simiyu G, Mwangi AW, Wools-Kaloustian $\mathrm{K}$, et al. Factors Associated with Late Engagement to HIV Care in Western Kenya A Cross-Sectional Study. J Int Assoc Provid AIDS Care. 2015. doi:10. 1177/2325957414567682

35. Palella FJ, Armon C, Chmiel JS, Brooks JT, Hart R, Lichtenstein K, et al. CD4 cell count at initiation of ART, long-term likelihood of achieving CD4 > 750 cells/mm 3 and mortality risk. J Antimicrob Chemother. 2016. doi:10.1093/ jac/dkw196 [Epub ahead of print].

36. Mutisya M, Nb K, Mw N, Cw K. Household food (in)security and nutritional status of urban poor children aged 6 to 23 months in Kenya. 2015; 12889. doi:10.1186/s12889-015-2403-0.Household

37. Nickanor N, Ln K. Increasing Levels of Urban Malnutrition with Rapid Urbanization in Informal Settlements of Katutura, Windhoek : Neighbourhood Differentials and the Effect of Socio-Economic Disadvantage. World Heal Popul. 2016;16:5-21.

38. Neupane S, Prakash K, David TD. Overweight and obesity among women: analysis of demographic and health survey data from 32 Sub-Saharan African Countries. BMC Public Health. 2016:16:30

39. World Bank. Poverty headcount ratio at $\$ 1.90$ a day (2011 PPP) [Internet]. 2011 [cited 10 Jan 2017]. Available: http://data.worldbank.org/indicator/SI. POV.DDAY?locations=ZG-ZW\&view=chart. Accessed 12 Dec 2016. 
40. Mutasa-Apollo T, Shiraishi RW, Takarinda KC, Dzangare J, Mugurungi O, Murungu $J$, et al. Patient retention, clinical outcomes and attrition-associated factors of HIV-infected patients enrolled in Zimbabwe's National Antiretroviral Therapy Programme, 2007-2010. PLoS One. 2014;9:e86305. doi:10.1371/journal.pone.0086305.

41. Cornell M, Schomaker M, Garone DB, Giddy J, Hoffmann CJ, Lessells R, et al. Gender Differences in Survival among Adult Patients Starting Antiretroviral Therapy in South Africa: A Multicentre Cohort Study. PLoS Med. 2012;9:1-12. doi:10.1371/journal.pmed.1001304.

42. Staveteig S, Shanxiao W, Head SK, Bradley SE, Nybro E. Demographic Patterns of HIV Testing Uptake in Sub-Saharan Africa. DHS Comoparative Reports No. 30. Calverton, Maryland: ICF International; 2013

43. Finkelstein JL, Gala P, Rochford R, Glesby MJ, Mehta S. HIV/AIDS and lipodystrophy: Implications for clinical management in resource-limited settings. J Int AIDS Soc. 2015;18:19033. doi:10.7448/IAS.18.1.19033.

44. Hemkens LG, Bucher HC. HIV infection and cardiovascular disease. Eur Heart J. 2014;35:1373-81. doi:10.1093/eurheartj/eht528.

45. Lake JE, Currier JS. Metabolic disease in HIV infection. Lancet Infect Dis. 2013;13:964-75. doi:10.1016/S1473-3099(13)70271-8.

46. Church TS, Thomas DM, Tudor-Locke C, Katzmarzyk PT, Earnest CP, Rodarte $R Q$, et al. Trends over 5 decades in U.S. occupation-related physical activity and their associations with obesity. PLoS One. 2011;6:e19657. doi:10.1371/ journal.pone.0019657.

47. Tareque MI, Koshio A, Tiedt AD, Hasegawa T. Are the rates of hypertension and diabetes higher in people from lower socioeconomic status in Bangladesh? Results from a nationally representative survey. PLoS One. 2015;10:e0127954. doi:10.1371/journal.pone.0127954.

48. May M, Boulle A, Phiri S, Messou E, Myer L, Wood R, et al. Prognosis of patients with HIV-1 infection starting antiretroviral therapy in sub-Saharan Africa: A collaborative analysis of scale-up programmes. Lancet. 2010;376: 449-57. doi:10.1016/S0140-6736(10)60666-6.

49. Filteau S, PrayGod G, Kasonka L, Woodd S, Rehman AM, Chisenga M, et al. Effects on mortality of a nutritional intervention for malnourished HIVinfected adults referred for antiretroviral therapy: a randomised controlled trial. BMC Med. 2015;13:17. doi:10.1186/s12916-014-0253-8.

50. Rehman AM, Woodd S, PrayGod G, Chisenga M, Siame J, Koethe JR, et al. Effects on anthropometry and appetite of vitamins and minerals given in lipid nutritional supplements for malnourished HIV-infected adults referred for antiretroviral therapy: results from the NUSTART randomized controlled trial. J Acquir Immune Defic Syndr. 2015;68:405-12. doi:10.1097/QAI. 0000000000000483

51. Cantrell RA, Sinkala M, Megazinni K, Lawson-Marriott S, Washington S, Chi $\mathrm{BH}$, et al. A pilot study of food supplementation to improve adherence to antiretroviral therapy among food-insecure adults in Lusaka, Zambia. J Acquir Immune Defic Syndr. 2008:49:190-5. doi:10.1097/QAl.0b013e31818455d2.

52. Ndirangu M, Sztam K, Sheriff M, Hawken M, Arpadi S, Rashid J, et al. Perceptions of Food-insecure HIV-positive Adults Participating in a Food Supplementation Program in Central Kenya. J Heal Care Poor Underserved. 2014;25:1763-83. doi:10.1353/hpu.2014.0153.

53. Harries AD, Kumar AMV, Satyanarayana S, Lin Y, Takarinda KC, Tweya H, et al. Communicable and non-communicable diseases: connections, synergies and benefits of integrating care. Public Heal Action. 2015;5:156-7. doi:10 5588/pha.15.0030

\section{Submit your next manuscript to BioMed Central and we will help you at every step:}

- We accept pre-submission inquiries

- Our selector tool helps you to find the most relevant journal

- We provide round the clock customer support

- Convenient online submission

- Thorough peer review

- Inclusion in PubMed and all major indexing services

- Maximum visibility for your research

Submit your manuscript at www.biomedcentral.com/submit 